\title{
Introduction to DOK2 and its Potential Role in Cancer
}

\author{
Pei SUN ${ }^{1^{*}}$, Rumeng LI $^{1^{*}}$, Yingying MENG ${ }^{1,2^{*}}$, Shijun XI ${ }^{1}$, Qinqi WANG ${ }^{1}$, Xiulan YANG ${ }^{3}$, \\ Xiaochun PENG ${ }^{1,4}$, Jun CAI ${ }^{5}$ \\ * These authors contributed equally to this work.
}

${ }^{1}$ Laboratory of Oncology, Center for Molecular Medicine, School of Basic Medicine, Health Science Center, Yangtze University, Jingzhou, China, ${ }^{2}$ Department of Gastroenterology, the Affiliated Hospital of Xuzhou Medical University, Xuzhou, China, ${ }^{3}$ Department of Pharmacology, School of Basic Medicine, Health Science Center, Yangtze University, Jingzhou, China, ${ }^{4}$ Department of Pathophysiology, School of Basic Medicine, Health Science Center, Yangtze University, Jingzhou, China, ${ }^{5}$ Department of Oncology, First Affiliated Hospital of Yangtze University, Jingzhou, China

Received April 22, 2021

Accepted May 26, 2021

Epub Ahead of Print September 10, 2021

\section{Summary}

Cancer is a complex, multifactorial disease that modern medicine ultimately aims to overcome. Downstream of tyrosine kinase 2 (DOK2) is a well-known tumor suppressor gene, and a member of the downstream protein DOK family of tyrosine kinases. Through a search of original literature indexed in PubMed and other databases, the present review aims to extricate the mechanisms by which DOK2 acts on cancer, thereby identifying more reliable and effective therapeutic targets to promote enhanced methods of cancer prevention and treatment. The review focuses on the role of DOK2 in multiple tumor types in the lungs, intestines, liver, and breast. Additionally, we discuss the potential mechanisms of action of DOK2 and the downstream consequences via the Ras/MPAK/ERK or PI3K/AKT/mTOR signaling pathways.

\section{Key words}

Tumor • DOK2 • Tyrosine phosphorylation • EGFR • SHIP-1 • DOK family

\section{Corresponding authors}

X. Yang, Department of Pharmacology, School of Basic Medicine, Health Science Center, Yangtze University, 1 Nanhuan Road, Jingzhou, Hubei 434023, China. E-mail: 406490115@qq.com or X. Peng, Department of Pathophysiology, School of Basic
Medicine, Health Science Center, Yangtze University, 1 Nanhuan Road, Jingzhou, Hubei 434023, China. E-mail: pxcwd789@sina.com or J. Cai, Department of Oncology, First Affiliated Hospital of Yangtze University, 1 Nanhuan Road, Jingzhou, Hubei 434023, China. E-mail: 529369023@qq.com

\section{Introduction to DOK2}

There are seven members of the DOK family of proteins downstream of tyrosine kinase, namely DOK1-7. DOK1 and DOK2 are able to recruit p120rasGAP, thereby inhibiting the Ras-MAPK-ERK pathway, playing important roles in cell growth and development. DOK3 can negatively regulate activation of c-Jun N-terminal kinase (JNK) and $\mathrm{Ca}^{2+}$ mobilization. In addition, DOK3 also binds the structural domains, inositol-5-phosphatase (SHIP-1) and growth factor receptor-bound protein2 (Grb2), which are involved in cellular regulation. Although DOK4, DOK5, and DOK6 do not modify the Ras pathway, they are expressed in a variety of nerve tissues, together with Glial cell-derived neurotrophic factor receptor C (c-Ret), playing an important role in the growth and development of nerve cells. Additionally, DOK7 has been shown to be important in the formation of neuromuscular synapses (Grimm et al. 2001, Mashima

PHYSIOLOGICAL RESEARCH • ISSN 1802-9973 (online) - an open access article under the CC BY-NC-ND 4.0 license (c) 2021 Institute of Physiology of the Czech Academy of Sciences, Prague, Czech Republic Fax+420 241062 164, e-mail: physres@fgu.cas.cz,www.biomed.cas.cz/physiolres 
et al. 2009, Ueta et al. 2017). The principal focus of the present manuscript is DOK2, also known as DOKR and FRIP, a member of the DOK family located on human chromosome 8p21.3 and a well-known tumor suppressor gene. As a member of the joint protein tyrosine kinase family, DOK2 acts through tyrosine kinase epidermal growth factor receptor (EGFR), platelet-derived growth factor receptor (PDGFR), and human epidermal growth factor receptor (Her-2/NEU-8) via negative feedback modulation of the signal transduction of protein tyrosine kinase (PTK). In addition, DOK2 can also suppress the activity of receptor tyrosine kinases. Src family kinases recruit $\mathrm{C}$-Src tyrosine kinase (Csk), which inhibits mitogen-activated protein kinase (MAPK) and Akt (also known as Protein Kinase B) phosphorylation, which influence DOK2 and which can be stimulated by EGF (Mashima et al. 2013, Jones et al. 1999, Suzu et al. 2000, Berger et al. 2013, Van et al. 2005). The DOK family has a common topological structure, namely a homologous domain (PH) at the N-terminal, a central tyrosine phosphorylation binding domain (PTB), and C-terminal $\mathrm{SH} 2$ and $\mathrm{SH} 3$ target sequences (PRR). The $\mathrm{PH}$ sequence is mainly involved with tyrosine phosphorylation and cell membrane localization of proteins (Suzu et al. 2000). The PTB is not only associated with tyrosine phosphorylation but also binds to the PTB sequence on EGFR, resulting in a series of cascade reactions (Jones et al. 1999). The PTB domain is an intracytoplasmic portion of the DOK protein. PTB contains NPXY and NXXY motifs through which it can bind to cell surface receptors (Smith et al. 2006). SH2 and SH3 domains at the C-terminal have seven PXXP motifs containing not only tyrosine phosphorylation residues and proline, but also RasGAP, Nck, Csk, and SHIP-1 sites, producing a cascade reaction (Di et al. 1998). When undergoing stimulation by a growth factor, DOK proteins become localized to the membrane signaling complex under the influence of $\mathrm{PH}$ and PTB domains, with increasing numbers of proteins that are recruited to participate in cascade reactions under the action of the PXXP motif and tyrosine phosphorylation residues on SH2 and SH3 (Berger et al. 2013). The present study will focus on the relationship between DOK2 and cancer, and so introduce the functions of DOK2, as displayed in Figure 1.

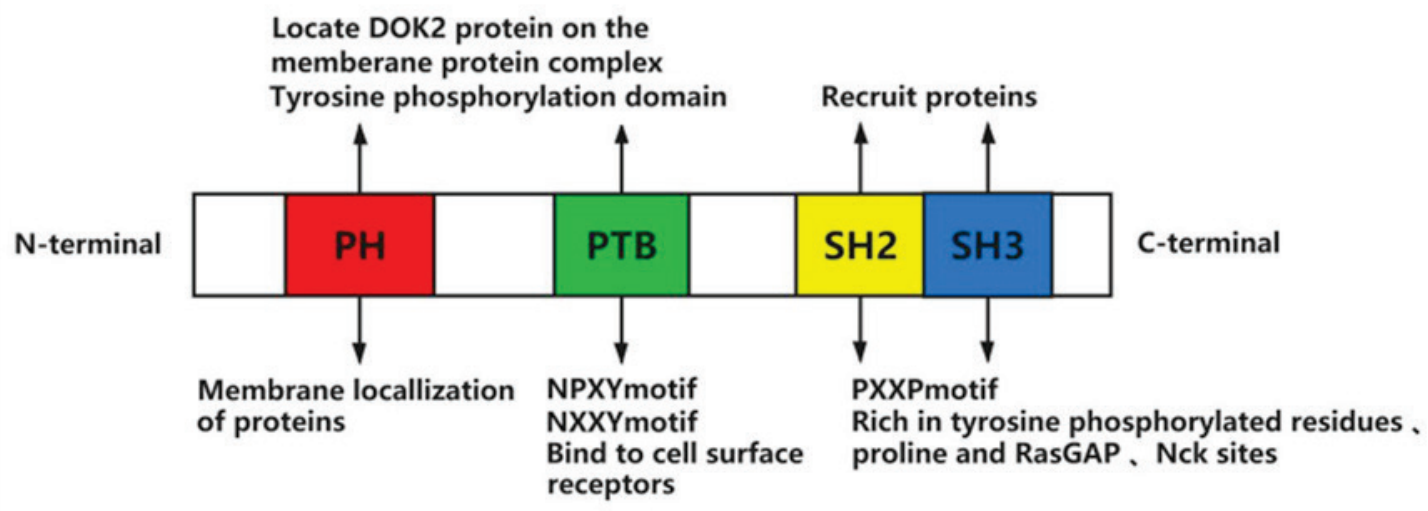

Fig. 1. DOK2 domain and potential function. The SH domain is at the DOK2 C-terminus. The Pleckstrin homology domain (PH) is connected at the $\mathrm{N}$-terminal of DOK2 and promotes protein-protein interactions.

\section{DOK2 and physiological cellular function}

\section{DOK2 and cell fusion and proliferation}

Kajikawa et al. demonstrated that DOK2 is expressed in both macrophages and monocytes in blood, with DOK2 regulating multiple signaling pathways via negative feedback which affects osteoclast proliferation. In a mouse model in which the DOK1 and DOK2 genes had been knocked out, animals were found to have larger numbers of osteoclasts and were more likely to develop symptoms of bone deficiency than wild-type mice (Kajikawa et al. 2018). In addition to bone, the downregulation or deletion of DOK 1 and DOK2 from blood has been shown to increase the incidence of chronic myelogenous leukemia and myeloproliferative diseases. The deletion or low expression of the DOK2 gene promotes the fusion and proliferation of a number of cell types. DOK1 and DOK2 regulate the development and function of natural killer (NK) cells, which play an important role in the immune response and tumor inhibition. Overexpression of DOK proteins in human NK cells can stimulate the activation of receptors on NK cells and thus inhibit their activity. In mice, the deletion of DOK1 and DOK2 genes has been shown to 
cause maturation defects in NK cells and increase the release of the cytokine interferon gamma (IFN- $\gamma$ ) (CelisGutierrez et al. 2014). Furthermore, cell proliferation and differentiation are regulated by cytokines that bind to their corresponding receptors, which activate a variety of tyrosine kinases, including JAK kinases and Src family kinases. In turn, cytokines can also stimulate DOK2 phosphorylation. Studies have demonstrated that the expression of DOK2 in M-NFS-60 cells causes the release of a large number of cytokines that inhibit cellular proliferation and differentiation (Suzu et al. 2000).

DOK2 and regulation of the cell cycle of hematopoietic stem and progenitor cells

Coppin et al. (2016) demonstrated that DOK1 and DOK2 play significant roles in the proliferation of myeloid cells. In elderly mice, the downregulation or deletion of DOK1 and DOK2 induces myeloproliferative disease. Greater graft survival and transient medullary amplification capability have been observed in hematopoietic stem cells after the knockout of DOK1 and DOK2 genes. In hematopoietic progenitor cells, the expression of DOK 1 and DOK2 inhibits the cell cycling of hematopoietic progenitor cells, thus affecting their proliferation. Therefore, DOK1 and DOK2 can regulate the signaling pathways of hematopoietic cell growth and differentiation and therefore, they affect the growth of myeloid hematopoietic cells.

\section{DOK2 and platelet regulation}

Hughan et al. confirmed that DOK2 plays an important role in integrin-induced signal transduction from extracellular stimuli to intracellular signaling (Hughan et al. 2000). In addition, immune complexes formed by DOK2 and integrin $\alpha \mathrm{II} \beta 3$ are also expressed downstream of $\mathrm{Src}$ family kinases. DOK2 plays an important role in regulating the physiological function of platelets since thrombin and $\alpha I I \beta 3$ receptors on platelets can stimulate the phosphorylation of platelet tyrosine residues. It has been shown that DOK2 is regulated in platelet-derived microparticles (PMPs) following stimulation by other platelets (Bidkhori et al. 2013). In addition, DOK2, a platelet-specific collagen receptor glycoprotein V1 (GPVI) signaling protein, has been found to undergo a higher level of tyrosine phosphorylation in response to the GPV1-specific agonist CRP (collagen-related peptide), a significant factor at sites of coronary artery occlusion (Vélez et al. 2016).
DOK2 is a negative regulator of T-cell receptor signaling It has been proposed by Yasuda et al. that DOK2 functions as a negative regulator of T-cell receptor signaling. The interaction between a TCR complex and an antigenic peptide is a central event in the immune response. It has been observed that the response in mice to thymo-dependent antigens and the response of T-cells to TCR stimulation is enhanced in the absence of DOK1 and DOK2, principally manifested as the tyrosine phosphorylation activation of ZAP-70, the proliferation of T-cells, and production of cytokines (Yasuda et al. 2007). DOK proteins play key roles in establishing a T-cell signal negative feedback loop. These structurerelated adaptor molecules contain a Pleckstrin homology (PH) domain, usually a lipid/protein interaction module. Experiments conducted by Guittard et al. demonstrated that the $\mathrm{PH}$ domain is required for DOK phosphorylation which triggered DOK1 and DOK2 inhibition in activated T-cells, while it has been found that the tyrosine phosphorylation of DOK1 and DOK2 proteins can be induced by inositol 5-phosphatase containing $\mathrm{SH} 2$ domains produced by T-cells, triggered by TCR (Guittard et al. 2009). DOK1 and DOK2 play key roles in the linker for activation of T-cells (LAT)-dependent negative feedback loop, which attenuates early TCR signaling. However, TCR can induce polymolecular complexes, including DOK2, SHI-1, and GRB-2, which assemble into LAT. LAT and SHI-1 also mediate tyrosine phosphorylation in DOK2. When DOK1 and DOK2 are inhibited, TCR-mediated IL-2 production and signaling transduction have been found to be enhanced (Dong et al. 2006). CD4 can enhance the sensitivity of the T-cell interaction with antigen peptide/MHC II molecular complexes. Waterman et al. demonstrated that CD4 aggregation leads to LCk-dependent phosphorylation of the RasGAP adaptor downstream of DOK-1/2 and inositol 5-phosphatase-1 (SHIP-1), leading to the binding of these two molecules. They hypothesized that the loss of function in $\mathrm{CD}^{+}{ }^{+} \mathrm{T}$-cells in HIV-1 may be due to the aggregation of gp120 with $\mathrm{CD} 4$ and subsequent inhibition of TCR activation in SHIP-1 and DOK1/2 pathways. It has been established that the SHIP pathway is necessary for CD4-mediated inhibition of calcium mobilization and proliferation of TCR stimulation activation (Waterman et al. 2012). Retrovirus-mediated expression of DOK2 kinase-related protein, also known as DOK-R, in bone marrow cells has been shown by Gugasyan et al. to significantly inhibit the cytokinedependent colony formation of hematopoietic progenitor 
cells, reduce the proliferation of thymus cells, and selectively inhibit the development of T-lymphocytes (Gugasyan et al. 2002).

\section{DOK2 and tyrosine channels}

DOK2, a downstream product of tyrosine kinase negatively regulates the signaling pathway of tyrosine kinase. DOK2 inhibits MAPK and Akt signaling, thus inhibiting cell proliferation and migration via two forms of inhibitory mechanism. It has been shown that DOK2 recruitment of the negative regulator of Ras signaling in the Ras-Raf-MAPK pathway inhibits MAPK activity, while DOK2 inhibits Akt phosphorylation through the phospholipinositol 3-carboxykinase (PI3K)-Akt pathway (Niki et al. 2004). In T-cells, for example, it has been found that DOK2 inhibits tyrosine phosphorylation and the Ras signaling pathway, thereby participating in the negative feedback regulation of Tec (Gérard et al. 2004). In human bone marrow cells, CD200R directly recruits DOK2 and activates RasGAP, thereby inhibiting bone marrow cells to become activated (Mihrshahi et al. 2009). Toll-like receptor II (TLR-2) strengthens DOK2 phosphorylation, with negative feedback modulating RasERK activation (Downer et al. 2013). After stimulation by EGF, DOK2 becomes phosphorylated, directly combining with EGFR tyrosine phosphate, then with Src family kinase (SFK) under the action of Csk, which inhibits MAPK, ERK, and Ras pathways, exacerbated by EGF (Berger et al. 2013, Van et al. 2005, Asati et al. 2016). The combination of platelet-derived growth factor (PDGF) and PDGFR facilitates the phosphorylation of DOK2, thereby inhibiting the PI3K-Akt signaling pathway. Like DOK2, insulin, and insulin-like growth factor expression suppress the PI3K-Akt-mTOR and Ras-MAPK pathways (Solarek et al. 2019). Early research demonstrated that Lck tyrosine kinase participates in signal transduction through T-cell surface receptors, such as TCR/CD3, CD2, and CD28. Ne'Morin et al. found that the cell surface receptor $\mathrm{CD} 2$ mediates Lck activation leading to specific phosphorylation of RasGAP, P56DOK (DOK2), and P62DOK (DOK1) (Némorin et al. 2000). In addition, they also demonstrated that phosphorylation of Ras GAP, DOK2, and DOK1 is associated with increased intracellular $\mathrm{Ca}^{2+}$ concentration and that the association between Lck and DOK1 is formed through an SH2-mediated interaction. They also found that the phosphorylated tyrosine (PTB) binding domain of DOK2 and DOK1 mediates their isotypic and heterologous interactions.
PTB-mediated oligomerization of DOK-1 and DOK-2 has been shown to be a requirement for DOK tyrosine phosphorylation and functionality (Boulay et al. 2005).

DOK2 is a negative regulator of lipopolysaccharideinduced signaling

Endotoxin is a form of bacterial lipopolysaccharide (LPS). Shinohara et al. demonstrated that DOK1 and DOK2 are negative regulators of tumor necrosis factor $\alpha(\mathrm{TNF}-\alpha)$ and nitric oxide (NO) produced after treatment of macrophages with LPS. DOK1 and DOK2 are known to be important adapters of the negative regulation of ERK. Shinohara verified that forced expression of DOK1 and DOK2 inhibits LPS-induced ERK activation and TNF- $\alpha$ production. It was also found that mice lacking DOK1 and DOK2 are allergic to LPS (Guittard et al. 2009).

\section{DOK2 and type I Fc receptors}

The expression of type I Fc receptors (FcIR) on mast cells causes activation of a biochemical cascade reaction, leading eventually to the release of inflammatory cytokines and a change in cell morphology and adhesion. It has been found that DOK1 and DOK2 are involved in an FcIR cascade in mucosal-type cells in RBL-2H3 rats. FcIR has also been shown to stimulate the phosphorylation of DOK1 and DOK2 through tyrosine (Abramson et al. 2007). In addition, DOK1 and DOK2 may also be key to cell cytoskeletal rearrangements following FcIR stimulation.

\section{DOK2 regulates memory $C D 8+T$-cells}

The strength and nature of TCR signaling affect the differentiation and function of effector and memory CD8+ T-cells. DOK1 and DOK2 are expressed on T-cells and negatively regulate the TCR signaling pathway in vitro. Laroche et al. investigated the role of DOK1 and DOK2 proteins in the regulatory response of $\mathrm{CD} 8+$ T-cells to vaccinia viral infection (Laroche et al. 2016). The response of wild-type cells to cowpox virus expressing the OVA peptide SIIFEKL was compared to that of CD84 OT-1 cells in which both DOK1 and DOK2 were silenced. They found that CD8- T-cell proliferation was inhibited because the T-cells displayed serious survival defects. In addition, CD8+ T-cells expressing DOK1 and DOK2 were also found to express TCR on their cell surface following stimulation by viral antigens in vivo, thus promoting the expression of granzyme $\mathrm{B}$ and $\mathrm{TNF}$ in vitro. This indicates that DOK1 and DOK2 
negatively regulate the overactivation of $\mathrm{CD} 8+\mathrm{T}$-cells and promote the formation of memory cells.

\section{DOK2 with CD200 and CD200R}

It has been shown that the interaction between membrane glycoprotein CD200 and its homologous receptor CD200R plays an important role in the static maintenance of microglia (Lyons et al. 2012). DOK2 phosphorylation is a key event that mediates the role of CD200 fusion protein $(\mathrm{CD} 200 \mathrm{FC})$ because DOK2 deletion blocks the activation of $\mathrm{CD} 200 \mathrm{FC}$ on microglia cells and the production of cellular inflammatory cytokines. CD200R is located in the cytoplasm and has 67 amino acids, containing 3 tyrosine residues and an NPXY motif. The interaction between CD200 and CD200R induces phosphorylation of these residues, initiating a signaling cascade and recruitment of DOK1 and DOK2 proteins, which activate RasGAP and SHIP, SH2-containing proteins. CD200R and DOK2 can stimulate microglia proliferation, and so CD200R and DOK2 may play roles in neurodegenerative diseases. The CD200/CD200R pathway is also of great significance for the treatment of leukemias. Viruses can mimic host proteins that produce $\mathrm{CD} 200$ and suppress the host antiviral response. Therefore, CD200 is also a marker of human cancer or cancer stem cells. Viruses suppress immune recognition, leading to immune escape by inhibition of activated white blood cells bearing CD200R (Mihrshahi et al. 2010). In human medullary cells, CD200R is able to recruit DOK1 and DOK2, thereby inhibiting the Ras pathway. Furthermore, it has also been found that DOK2 can directly interact with the NPXY motif in human CD200R, leading to the activation of RasGAP, thereby inhibiting the activation of human medullary cells (Rijkers et al. 2007). In mouse medullary mast cells, CD200R is phosphorylated on tyrosine residues following the binding with its ligand, followed by binding to DOK1 and DOK2. It has been found that DOK1 binds to SHIP, and both DOK1 and DOK2 recruit RasGAP, leading to the inhibition of the Ras-MAPK signaling pathway (Zhang et al. 2004, Zhang et al. 2006). Studies have also shown that CD200R1 may also be associated with head and neck squamous cell carcinoma due to the action of DOK2, as shown in Table 1 (Chang et al. 2020).

Table 1. Role of DOK2 and related factors in various physiological processes.

\begin{tabular}{ll}
\hline Physiological processes & DOK2 and DOK2-associated factors \\
\hline $\begin{array}{l}\text { Cell fusion and proliferation } \\
\text { Regulation of the cell cycle of hematopoietic stem and } \\
\text { progenitor cells }\end{array}$ & DOK2, DOK1, DOK3, IFN- $\gamma$ \\
Regulation of platelets & DOK2, DOK1 \\
Negative regulators of T cell receptor signaling & DOK2, $\alpha$ II $\beta 3$ \\
Tyrosine channel & DOK2, ZAP-70, SHIP-1, Grb-2, CD4, RasGAP, gp120 \\
Negative regulators of Lipopolysaccharide-induced & DOK2, EGFR, RasGAP, TLR-2 \\
signals & DOK2, LPS, TNF- $\alpha$, ERK \\
FcIR & DOK2, FcIR \\
Modulation of memory CD8+ T cells & DOK2, DOK1 \\
CD200 and CD200R & DOK2, CD200, CD200R, GasGAP \\
\hline
\end{tabular}

\section{DOK2 and pathology}

\section{DOK2 and herpes simplex virus 1}

After herpes simplex virus-1 (HSV-1) infection, viral envelope protein vp11/12 can bind to DOK2 through its SHC-binding motif, inducing tyrosine phosphorylation and selective degradation of DOK2. Lahmidi et al. speculated that this may be an immune escape mechanism through inactivation of $\mathrm{T}$-cells or inhibition of T-cell immune function (Lahmidi et al. 2017). When HSV-1 becomes a latent infection, DOK2 can promote the survival of HSV-1-specific CD8+ T-cells in lymphoid tissues, such as the spleen and draining lymph nodes, and also non-lymphoid tissues, such as the cornea and trigeminal ganglion (TG). Its deficiency has been shown to promote activation of latent HSV-1 in vitro (Lahmidi et al. 2017). 


\section{DOK2 and glial inflammation}

Toll-like receptor 2 (TLR-2) is a bridge between specific and nonspecific immunity, through recognition of pathogen-related molecular patterns, triggering signal transduction and leading to the release of inflammatory mediators. Studies by Downer and others have shown that TLR-2 enhances tyrosine phosphorylation of DOK1 and DOK2 in astrocytes and microglia. In astrocytes transfected with DOK1 and DOK2 siRNA, the production of NF- $\mathrm{kB}$ and IL- 6 induced by TLR-2 was found to be enhanced, indicating that DOK1 and DOK2 proteins affect the release of inflammatory mediators induced by TLR-2 through negative feedback regulation (Solarek et al. 2019).

\section{DOK2 and leishmaniasis infection}

Previous studies have shown that DOK1, DOK2, and DOK3 are targets of GP63, a metalloprotein associated with Leishmania. Álvarez de Celis et al. found that tumor necrosis factor and nitric oxide expression declined in macrophages lacking DOK1 and DOK2 expression treated with $\Delta \mathrm{gp} 63$ protein or wild type L. major promastigotes compared with wild-type macrophages, indicating that DOK proteins may be an important regulatory factor in macrophages infected with Leishmania (Álvarez et al. 2015).

\section{DOK2 and peritoneal fibrosis}

Peritoneal fibrosis (PF) is a recognized complication associated with continuous peritoneal dialysis, characterized by early reversible epithelial to mesenchymal transition (EMT) (Zhang et al. 2019). The long noncoding RNA AK089579 inhibits EMT in peritoneal stromal cells (PMC) by the competitive binding of microRNA-296-3p to DOK2. As is well known, DOK2 is a target gene of miRNA296, so AK089579 can regulate the expression of DOK2 by regulation of miRNA296 through the JAK2-STAT3 signaling pathway. AK089579 can inhibit the activation of the JAK2-STAT3 signaling pathway, and indirectly upregulate the expression of DOK2 by combining with miRNA296, thus inhibiting migration, invasion, and EMT in the PMC in a murine model of PF. In addition, upregulation of miRNA296 and down-regulation of DOK2 were found to display opposite effects. In conclusion, DOK2 may play a key role in PF, as shown in Table 2.

Table 2. Role of DOK2 and related factors in various pathophysiological processes.

\begin{tabular}{ll}
\hline Pathological process & DOK2 and DOK2-associated factors \\
\hline Peritoneal fibrosis & DOK2, lncRNA (AK089579), JAK2/STAT3 \\
Herpes simplex virus 1 (HSV-1) & DOK2, Vp11/12, DOK1 \\
Glial inflammation & DOK2, TLR-2, IL-6 \\
Leishmania infection & DOK2, DOK1, DOK3, GP63 \\
\hline
\end{tabular}

\section{DOK2 and tumors}

\section{DOK2 and colorectal cancer}

Colorectal cancer is the most common malignant tumor of the digestive system. Its morbidity and mortality are on the rise, currently ranking third among malignant tumors. Although many forms of treatment can improve the postoperative survival of patients with colorectal cancer, biomarkers for early diagnosis and poor prognosis of colorectal cancer remain lacking. Thus, it remains an important goal to identify new biomarkers for the disease. Research by Wen et al. indicates that of 102 patients with postoperative colorectal cancer, $33.3 \%$ did not express DOK2, a subgroup that generally displayed poor prognosis, with a five-year survival rate of only $59.1 \%$. In comparison, the five-year survival rate of patients expressing DOK2 was as high as $76.4 \%$ $(P=0.0328)$. The expression of DOK2 was found to be low in 34 patients with poorly differentiated colorectal cancer. Compared with colon cancer tissue which is generally observed to have high DOK2 expression, highly differentiated and chronically differentiated adenomas lacked the expression of DOK2 (Wen et al. 2015). These observations suggest that low DOK2 expression may be a biomarker of poor prognosis in patients undergoing colorectal cancer resection. Moreover, DOK2 may also play an important role in its early diagnosis and treatment. However, at present, the consequences of low expression of DOK2 are not been fully understood, and additional studies are required to 
confirm the mechanism of DOK2 in the treatment of colorectal cancer and other cancers.

\section{DOK2 and leukemia}

The combined loss of DOK1 and DOK2 can trigger chronic myeloid leukemia (CML)-like myeloproliferative disease (MPD) when completely explicit. Their lack results in the proliferation or survival of hematopoietic cells in the presence or absence of growth factors, respectively. This indicates that both DOK1 and DOK2 play key synergistic roles in the homeostasis of hematopoiesis and inhibition of tumors, allowing resistance to p210 BCR-ABL-driven leukemia and lymph node formation (Niki et al. 2004). In a study published by Yasuda et al., it was revealed that DOK1 and DOK2 play synergistic roles in the negative regulation of a number of cytokines, except G-CSF (Yasuda et al. 2004). They also synergistically inhibit extracellular-regulated protein kinase (ERK) and protein kinase B (PKB) when stimulated synergistically by cytokines. In addition, DOK1 and DOK2 inhibit cytokine-mediated proliferation and anti-apoptotic signals in myeloid cells. In a study published by Niki et al., DOK1 and DOK2 were found to inhibit the development of myeloid leukemia and CML-like disease mutations in mice (Niki et al. 2004, Yasuda et al. 2004). DOK1 and DOK2 were also shown to prevent HL-60 cells from losing viability following long-term exposure to high serum levels. When induced by trans-retinoic acid (RA) and 1,25-dihydroxyvitamin D3 (VD3), ectopic expression of DOK2 was shown to increase in HL-60 cells following the arrest of growth, differentiation, and G0/G1 cell cycle arrest induced by RA and VD3, resulting in increased phosphorylation of extracellular regulated protein kinase (ERK1/2) (Lamkin et al. 2006).

Dasatinib has been found to inhibit the function of $\mathrm{c}-\mathrm{Abl}$ by reducing the phosphorylation of DOK2, a downstream target of $\mathrm{c}-\mathrm{Abl}$, during the treatment of primary chronic lymphoblastic leukemia (CLL), inducing H2AX phosphorylation, causing CLL lymphocytes to be sensitive to chlorambucil and fludarabin (Amrein et al. 2008). In chronic myeloid leukemia (CMML), DOK2 undergoes point mutation, affecting the DOK2 PTB domain. For example, the L238P mutation can modify the PTB domain, preventing binding to the phosphotyrosine peptide, and the tyrosine-phosphorylated DOK1 protein. It also leads to the loss of DOK2 functionality and the failure to inhibit ERK activation (Coppin et al. 2015). DOK2 and SHIP1 proteins are the most significant constitutive phosphorylation substrates of BCR-ABL kinase. In a study by Liang et al., DOK2 was found to be phosphorylated at tyrosine 299, while imatinib was shown to inhibit the tyrosine phosphorylation of DOK2 (Liang et al. 2006). In two groups of experiments by Ohsugi et al., it was first shown that, compared with uninfected T-cells, DOK2 expression is significantly reduced in transformed T-cells (MT-2 and hut-102) infected with HTLV-1, and TL-Om1 cells from adult T-cell leukemia/lymphoma (ATLL) patients (Ohsugi et al. 2016). They subsequently studied human T-cell leukemia virus type 1 transferred into mice. The HTLV-1 transgenic (TG) mice expressed DOK2 in mature thymocytes and peripheral lymphocytes. We have observed that DOK2 expression in TG mice is significantly lower than in non-TG mice prior to exhibiting disease symptoms, with the downregulation of DOK2 expression the first step in the development of disease characterized by low DOK2 gene expression (Ohsugi et al. 2017). Knockout of DOK2 mRNA in mouse erythrocytic leukemia cells with high DOK2 expression has been found to increase the expression of Kruppel like factor (KIf1). Experiments by Tanaka demonstrate that DOK2 binds directly to the KIf1 promoter, controlling KIf1 expression through transcriptional regulation (Tanaka et al. 2014). He et al. have also investigated the decreased expression of DOK1 and DOK2, finding an association with hypermethylation of the promoters, allowing prediction of adverse prognosis of acute myeloid leukemia (AML) (He et al. 2018).

\section{DOK2 and invasive histiosarcoma}

Mashima et al. obtained TKO mice by knockout of the DOK $1 / 2 / 3$ genes. The results demonstrate that invasive tissue sarcoma (HS) is significantly associated with a lethal phenotype in TKO mice, finding that the HS observed in the mice was highly invasive and transplantable. Abnormal aggregation of pulmonary macrophages in TKO mice was also observed, indicating that DOK $1 / 2 / 3$ are negative regulators of the macrophage response to macrophage colony-stimulating factor (G-CSF) and granulocyte macrophage colony-stimulating factor (GM-CSF) (Mashima et al. 2010).

\section{DOK2 and lung cancer}

In a study by Chen et al., DOK2 and Dusp4 were found to display both tumor suppressive and MAPK inhibitory functionality due to haploid deficiency. The 
complex heterozygosity of DOK2 and Dusp4 enhance sensitivity to MEK inhibition, and both inhibit MAPK activation and cell proliferation. It was found that DOK2 and Dusp4 heterozygosity synergistically promotes the occurrence of lung tumors (Chen et al. 2019). It is well known that DOK2 is a human lung tumor suppressor, and Berger et al. further confirmed that DOK2 is a target for genomic deletion and down-regulation of human lung cancer, with DOK2 able to inhibit the proliferation of lung cancer both in vitro and in vivo. They also concluded that single or compound knockout of DOK $1 / 2 / 3$ can cause lung cancer in mice and that the rate of incidence of lung adenocarcinoma increases with the number of missing alleles. It has been found that DOK2 expression in lung cancer cell lines is very low or undetectable (Berger et al. 2010). Berger has also demonstrated that DOK2 inhibits EGF-induced Ras and ERK activity, interacting with EGFR. In other words, the induction of EGFR activation by ligands or carcinogenic mutations induce DOK2 to recruit the EGF receptor complex and rasa1. In addition, DOK2 has been shown to inhibit the expansion of EGFR mutant lung adenocarcinoma cells (Berger et al. 2013).

\section{DOK2 and renal cancer}

Globally, renal cancer is the $16^{\text {th }}$ most common disease, with 403,262 new cases and 175,098 deaths in 2018. Solarek et al. compared HEK293 renal cancer cells with PCS-400-010 normal renal cells and evaluated cell growth, viability, and mobility following hormone stimulation, also measuring insulin and insulin-like growth factor 1 receptor (IGF-1) expression. The results indicate that insulin and IGF-1 promote the growth and migration of renal carcinoma cells (Solarek et al. 2019, Kužma et al. 2019). In addition, the expression of insulin and IGF-1 promote the expression of genes inhibitory to the PI3K-Akt-MTOR and RAS-MAPK signaling pathways, similar to the functions of genes such as DOK1, DOK2, INS, and FRS3. In addition, these genes also encode insulin receptor-related proteins, although they are not expressed in renal cancer cells. Therefore, this suggests that low DOK2 expression causes low insulin and IGF-1 expression, and so the rapid growth and migration of renal cancer.

\section{DOK2 and breast cancer}

Breast cancer is among the two most deadly cancers in women in Asia, with a very high incidence. Although the survival rate of patients with breast cancer is as high as $65 \%$ with advanced treatment, the identification of novel biomarkers for its early diagnosis and poor prognosis remains a challenge (Jambor et al. 2019). Huang et al. demonstrated that low expression of DOK2 and RASA1 is related to poor differentiation in breast cancer, and the deletion of DOK2 and RASA1 is related to increased tumor size, increased proportion of axillary lymph node metastasis, and higher clinical stage. The absence of DOK2 and RASA1 may cause activation of Ras extracellular signaling that regulates the kinase cascade, leading to cell cycle abnormalities that affect tumor size and metastasis (Huang et al. 2017, Ghanem et al. 2014, Zhang et al. 2020). Ghanem et al. found that decreased DOK2 mRNA expression in human breast cancer cells leads to higher TNM staging, while patients with high expression of DOK2 have a lower risk of recurrence and distant metastasis following surgical resection (Ghanem et al. 2014). When treating breast cancer, the lack of the DOK2 gene reduces the level of apoptosis leading to drug resistance. In addition, DOK2 promotes the recycling of EGFR by the C-Src inhibitor Csk that inhibits the activation of MAPK, which is closely related to the occurrence and development of breast cancer (Van et al. 2005). In summary, the deletion or low expression of DOK2 may represent low differentiation in breast cancer cells and related to poor prognosis in patients. Therefore, DOK2 may play an important role in the early diagnosis and treatment of breast cancer.

\section{DOK2 and glioma}

Glioma is the most common primary intracranial tumor, accounting for $27 \%$ of all tumors of the central nervous system (Herbet et al. 2018). Deshpande et al. (2018) confirmed that Nitidine chloride (NC), a wellknown anticancer drug, can recruit DOK2 and Caspase3 that affects the death of glioma in C6 mice and U87 human malignant glioma cells. Therefore, the overexpression of DOK2 protein may be related to poor prognosis in human glioma (Deshpande et al. 2018).

\section{DOK2 and lymphoma}

Lymphoma is not uncommon in China, with an incidence of 4-5 per 100,000 population, and so it is one of the ten most common malignant tumors. In patients with lymphomas, the disease is often caused by the multiple cloning of a cell with a particular TCR rearrangement, while it is also partly caused by loss of TCR expression. Therefore, we speculated that the TCR pathway may play an important role in the occurrence and development of T-cell lymphoma. 
Miyata-Takata et al. identified components of the TCR pathway in 91 formalin-fixed paraffin-embedded lymphatic tissues using immunohistochemical techniques. The results indicate that ZAP70 is expressed in $94 \%(83 / 88)$ of cases, GRAP2/GADS in $68 \%(60 / 68)$, DOK2 in $42 \%(38 / 90)$, LCK in $35 \%$ (31188), and ITK in $10 \%(9 / 90)$. Thus, iDOK2 appears to affect the TCR expression pathway and regulates the growth of T-cell lymphomas (Miyata et al. 2018). Furthermore, immunostaining of proteins suggests that DOK2 expression is also lower in both normal T-cells and those of lymphoma patients. It thus plays an important role in the differentiation of cells. Therefore, there may be a significant role for DOK2 in the treatment of T-cell lymphoma.

\section{DOK2 and astrocytoma}

Astrocytoma is a common malignant tumor of the brain. Although clinical research has made good progress, the median survival of patients with malignant astrocytoma remains very low. From 47 tissue samples of patients undergoing resection of astrocytoma, PCR and Western blot analysis has found that DOK2 protein is overexpressed in $83 \%$ of stage GIII and GIV astrocytoma, and in $30 \%$ of stage GII tissues. In a follow-up investigation, the median survival of patients in the DOK2-overexpression group was only 20 months (95\% CI: 0.083-0.49) (Deshpande et al. 2018). In conclusion, DOK2 overexpression is associated with poor prognosis in astrocytoma and may represent an effective target for its treatment.

\section{DOK2 and other tumors}

It has been shown that inhibition of DOK2 increases platinum resistance in ovarian cancer cells. In addition, loss of DOK2 protects against apoptosis and anoikis, that is, loss of DOK2 can induce resistance to carboplatin in ovarian cancer cells (Fang et al. 2018). Conversely, inhibition of DNA methylation has been found to leads to the upregulation of DOK2 expression, causing ovarian cancer cells to be sensitive to platinumbased drugs (Lum et al. 2013), and should be considered when Appraising the prognosis of ovarian cancer patients. Furthermore, the low frequency of missense mutants of DOK2 is significantly correlated with the increased incidence of pancreatic adenocarcinoma (PDAC) (Chang et al. 2013). Additionally, it can also be used as a marker of poor prognosis after radical mastectomy (Miyagaki et al. 2012), as shown in Table 3.

Table 3. Genes or proteins associated with DOK2 and the related cancers.

\begin{tabular}{ll}
\hline Cancer type & DOK2-associated gene or protein \\
\hline Colorectal cancer & DOK2 \\
Chronic myelogenous leukemia $(C M L)$ & DOK2, ERK, MAP, gp210 \\
Adult T-cell leukemia (ATL) & DOK2, Tax \\
Erythroleukemia & DOK2, KIf1 \\
Chronic lymphocytic leukemia & DOK2, Src \\
Aggressive histiocytic sarcoma (HS) & DOK2, DOK1, DOK3, M-CSF, GM-CSF \\
Lung cancer & DOK2, MAPK, Dusp4, EGFR \\
Renal cancer & DOK2, IGFs, Insulin \\
Breast cancer & DOK2, RASA1, MAPK, C-Src, Csk, EGFR \\
Glioma cancer & DOK2, NC \\
Lymphoma & DOK2, TCR \\
Astrocytoma & DOK2 \\
Ovarian cancer & DOK2 \\
Pancreatic cancer & DOK2 \\
Gastric cancer & DOK2 \\
\hline
\end{tabular}

\section{Mechanisms of action of DOK2}

DOK2 is a well-known tumor suppressor gene located on human chromosome $8 \mathrm{p} 21.3$ whose expression is downstream of tyrosine kinase, thereby affecting EGF-stimulated DOK2 phosphorylation. DOK2 operates through tyrosine kinase receptors, such as EGFR, PDGFR, and Her-2, with negative feedback regulating 
tyrosine kinase activity (Solarek et al. 2019, Chen et al. 2019, Ghanem et al. 2014). For example, DOK2 interacts with EGFR. Through the action of a Src family kinase, DOK2 activates EGFR, which inhibits the EGF-P13KAkt pathway, influencing the expression of related genes and proteins that inhibit cell proliferation and migration, promoting cell apoptosis and autophagy, which affects tumor development (Berger et al. 2013, Van et al. 2005). EGFR and RASA1 activation can also inhibit the EGF-RAS-MAPK-ERK pathway which inhibits cell division and affects the occurrence and development of tumors. In addition, DOK2 can recruit Csk family proteins that inhibit Src family kinase activity (Berger et al. 2013). However, EGFR activation also induces DOK2 recruitment to the EGFR complex and DOK2mediated recruitment of RASA1. DOK2 is also stimulated by epidermal growth factor, macrophage colony-stimulating factor (M-CSF), angiogenin-1 (Ang-1), interleukin-3 (IL-3), etc. DOK2 can be phosphorrylated when stimulated by these factors (Suzu et al. 2000, Master et al. 2001, Jones et al. 2003), as shown in Figure 2.

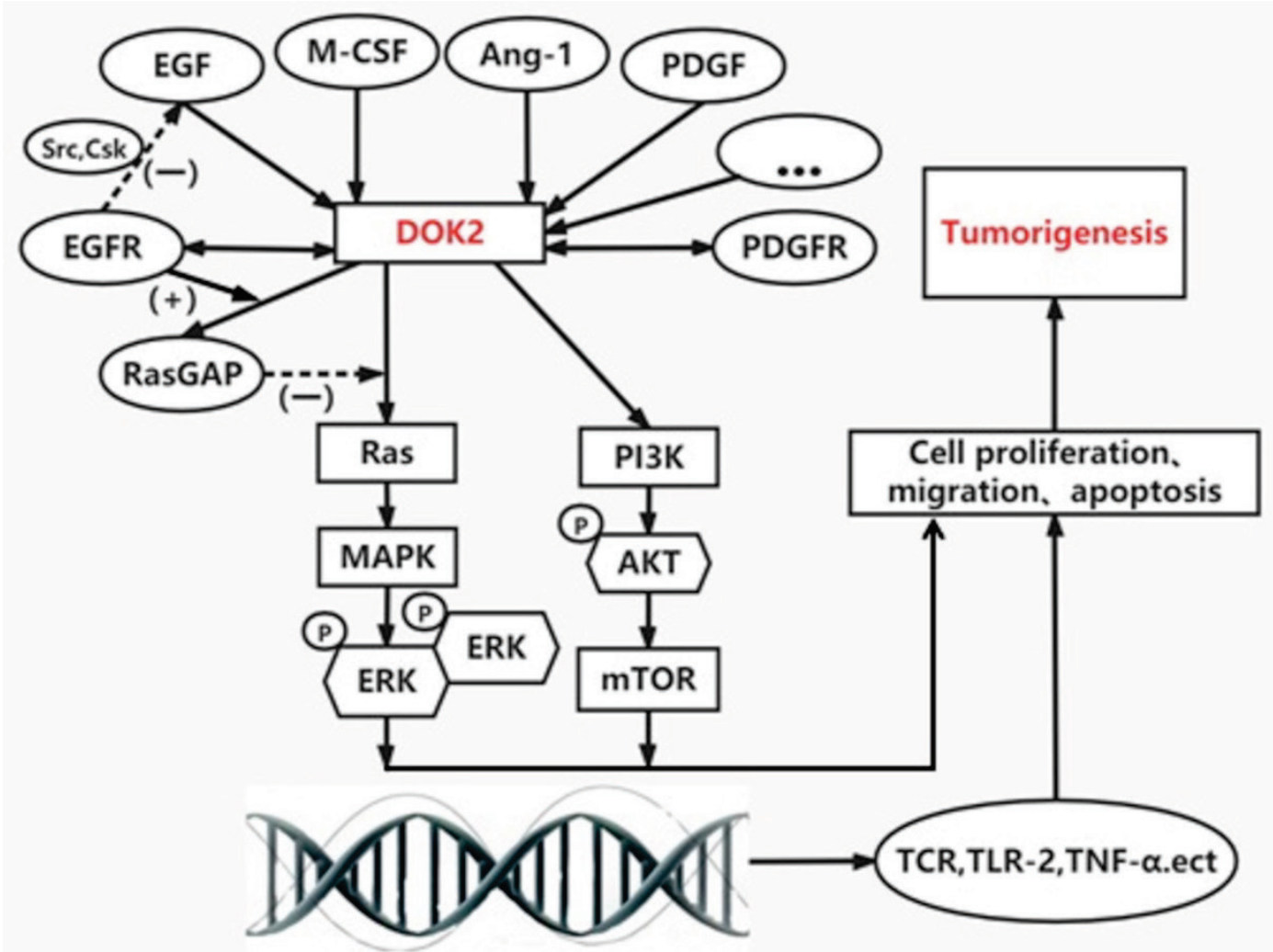

Fig. 2. Potential role of DOK2 in tumorigenesis. DOK2 is regulated by multiple factors such as EGF, PDGF, etc., which then regulate the Ras/PI3K signaling pathway causing abnormal cell proliferation and migration, ultimately leading to tumorigenesis.

\section{Conclusions}

DOK2 plays an important role in many physiological functions, especially negative regulation of the T-cell signaling pathway and growth and development of hematopoietic progenitor cells. Moreover, it is associated with multiple diseases, such as leukemia, invasive tissue sarcoma, herpes simplex virus (HSV-1), peritoneal fibrosis, etc. In addition, many reports have demonstrated that downregulation of DOK2 is related to the occurrence of cancer. Berger $e t$ al. have confirmed that DOK2 is a target of genomic deletion and down-regulation in human lung cancer (Berger et al. 2010). Therefore, genetic testing prior to the occurrence of cancer should predict the risk of disease in patients. Similarly, we can also select DOK2 as a therapeutic target for cancer treatment to block its carcinogenic mechanism in advance. For prognosis related to surgery, DOK2 is also of considerable value as a reference. For example, in ovarian cancer, upregulation of DOK2 causes ovarian cancer cells to again be sensitive to platinumbased drugs (Fang et al. 2018, Lum et al. 2013). Therefore, to prevent, treat, and evaluate prognosis of cancer patients, DOK2 is an important target, but not the 
one and only most important.

\section{Conflict of Interest}

There is no conflict of interest.

\section{Acknowledgements}

The study was supported by the Nature Science Foundation of Hubei Province (Grant No. 2017CFB786), Hubei Province Health and Family Planning Scientific Research Project (Grant No. WJ2016Y10), Jingzhou Science and Technology Bureau Project (Grant No. 201793), and National innovation and entrepreneurship training program for College Students (Grant No. 202010489017). All funding was granted to Dr. Peng.

\section{Abbreviations}

AML - acute myeloid leukemia, ATLL - adult T-cell leukemia/lymphoma, CD200FC - CD200 fusion protein,
CLL - chronic lymphoblastic leukemia, CMML chronic myeloid leukemia, Csk - C-Src tyrosine kinase, CML - chronic myeloid leukemia, DOK - downstream of tyrosine kinase, EGFR - epidermal growth factor receptor, EMT - epithelial to mesenchymal transition, ERK - extracellular-regulated protein kinase, FcIR - Fc receptors, GPVI - glycoprotein VI, Grb2 - growth factor receptor-bound protein 2, HSV-1 - herpes simplex virus1 , IFN- $\gamma$ - interferon gamma, IGF-1 - insulin-like growth factor, KIf1 - Kruppel-like factor, LPS lipopolysaccharide, MAPK - mitogen-activated protein kinase, MPD - myeloproliferative disease, $\mathrm{NC}$ - nitidine chloride, NK - natural killer, NO - nitric oxide, PDGFR - platelet-derived growth factor receptor, $\mathrm{PF}$ - Peritoneal fibrosis, PKB - protein kinase B, PTB - phosphorylation binding domain, PTK - protein tyrosine kinase, SFK Src family kinase, SHIP-1 - inositol-5-phosphatase, TLR2 - Toll-like receptor II, TNF- $\alpha$ - tumor necrosis factor $\alpha$.

\section{References}

ABRAMSON J, PECHT I: Regulation of the mast cell response to the type $1 \mathrm{Fc}$ epsilon receptor. Immunol Rev 217: 231-254, 2007. https://doi.org/10.1111/j.1600-065X.2007.00518.x

ÁLVAREZ DE CELIS H, GÓMEZ CP, DESCOTEAUX A, DUPLAY P: Dok proteins are recruited to the phagosome and degraded in a GP63-dependent manner during Leishmania major infection. Microbes Infect 17: 285-294, 2015. https://doi.org/10.1016/j.micinf.2014.12.011

AMREIN L, HERNANDEZ TA, FERRARIO C, JOHNSTONJ, GIBSON SB, PANASCI L, ALOYZ R: Dasatinib sensitizes primary chronic lymphocytic leukaemia lymphocytes to chlorambucil and fludarabine in vitro. Br J Haematol 143: 698-706, 2008. https://doi.org/10.1111/j.1365-2141.2008.07418.x

ASATI V, MAHAPATRA DK, BHARTI SK: PI3K/Akt/mTOR and Ras/Raf/MEK/ERK signaling pathways inhibitors as anticancer agents: Structural and pharmacological perspectives. Eur J Med Chem 109: 314-341, 2016. https://doi.org/10.1016/j.ejmech.2016.01.012

BERGER AH, NIKI M, MOROTTI A, TAYLOR BS, SOCCI ND, VIALE A, BRENNAN C, SZOKE J, MOTOI N, ROTHMAN PB, ET AL.: Identification of DOK genes as lung tumor suppressors. Nat Genet 42: 216-223, 2010. https://doi.org/10.1038/ng.527

BERGER AH, CHEN M, MOROTTI A, JANAS JA, NIKI M, BRONSON RT, TAYLOR BS, LADANYI M, AELST LV, POLITI K, VARMUS HE, PANDOLFI PP: DOK2 inhibits EGFR-mutated lung adenocarcinoma. PLoS One 8: e79526, 2013. https://doi.org/10.1371/journal.pone.0079526

BIDKHORI G, NARIMANI Z, HOSSEINI ASHTIANI S, MOEINI A, NOWZARI-DALINI A, MASOUDI-NEJAD A: Reconstruction of an integrated genome-scale co-expression network reveals key modules involved in lung adenocarcinoma. PLoS One 8: e67552, 2013. https://doi.org/10.1371/journal.pone.0067552

BOULAY I, NÉMORIN JG, DUPLAY P: Phosphotyrosine binding-mediated oligomerization of downstream of tyrosine kinase (Dok)-1 and Dok-2 is involved in CD2-induced Dok phosphorylation. J Immunol 175: 4483-4489, 2005. https://doi.org/10.4049/jimmunol.175.7.4483

CELIS-GUTIERREZ J, BOYRON M, WALZER T, PANDOLFI PP, JONJIĆ S, OLIVE D, DALOD M, VIVIER E, NUNÈS JA: Dok1 and Dok2 proteins regulate natural killer cell development and function. EMBO J 133: 1928-1940, 2014. https://doi.org/10.15252/embj.201387404 
CHANG H, LEE YG, KO YH, CHO JH, CHOI JK, PARK KU, KANG EJ, LEE KW, LIM SM, KIM JS, ET AL.: Prognostic value of CD200R1 mRNA expression in head and neck squamous cell carcinoma. Cancers 12: 1777, 2020. https://doi.org/10.3390/cancers12071777

CHEN M, ZHANG J, BERGER AH, DIOLOMBI MS, NG C, FUNG J, BRONSON RT, CASTILLO-MARTIN M, THIN TH, CORDON-CARDO C, PLEVIN R, PANDOLFI PP: Compound haploinsufficiency of Dok2 and Dusp4 promotes lung tumorigenesis. J Clin Invest 129: 215-222, 2019. https://doi.org/10.1172/JCI99699

CHANG J, TIAN J, ZHU Y, ZHONG R, ZHAI K, LI J, KE J, HAN Q, LOU J, CHEN W, ET AL.: Exome-wide analysis identifies three low-frequency missense variants associated with pancreatic cancer risk in Chinese populations. Nat Commun 9: 3688, 2018. https://doi.org/10.1038/s41467-018-06136-X

COPPIN E, GELSI-BOYER V, MORELLI X, CERVERA N, MURATI A, PANDOLFI PP, BIRNBAUM D, NUNÈS JA: Mutational analysis of the DOK2 haploinsufficient tumor suppressor gene in chronic myelomonocytic leukemia (CMML). Leukemia 29: 500-502, 2015. https://doi.org/10.1038/leu.2014.288

COPPIN E, DE GRANDIS M, PANDOLFI PP, ARCANGELI ML, AURRAND-LIONS M, NUNĖS JA: Dok1 and Dok2 proteins regulate cell cycle in hematopoietic stem and progenitor cells. J Immunol 196: 4110-4121, 2016. https://doi.org/10.4049/jimmunol.1501037

DESHPANDE RP, BABU PP: pDok2, caspase 3 dependent glioma cell growth arrest by nitidine chloride. Pharmacol Rep 70: 48-54, 2018. https://doi.org/10.1016/j.pharep.2017.07.013

DESHPANDE RP, CHANDRA SEKHAR Y, PANIGRAHI M, BABU PP: Region-specific Dok2 overexpression associates with poor prognosis in human astrocytoma. Mol Neurobiol 55: 402-408, 2018. https://doi.org/10.1007/s12035-016-0324-2

DI CRISTOFANO A, CARPINO N, DUNANT N, FRIEDLAND G, KOBAYASHI R, STRIFE A, WISNIEWSKI D, CLARKSON B, PANDOLFI PP, RESH MD: Molecular cloning and characterization of p56dok-2 defines a new family of RasGAP-binding proteins. J Biol Chem 273: 4827-4830, 1998. https://doi.org/10.1074/jbc.273.9.4827

DOWNER EJ, JOHNSTON DG, LYNCH MA: Differential role of Dok1 and Dok2 in TLR2-induced inflammatory signaling in glia. Mol Cell Neurosci 56: 148-158, 2013. https://doi.org/10.1016/j.mcn.2013.04.007

DONG S, CORRE B, FOULON E, DUFOUR E, VEILLETTE A, ACUTO O, MICHEL F: T cell receptor for antigen induces linker for activation of $\mathrm{T}$ cell-dependent activation of a negative signaling complex involving Dok-2, SHIP-1, and Grb-2. J Exp Med 203: 2509-2518, 2006. https://doi.org/10.1084/jem.20060650

FANG F, CARDENAS H, HUANG H, JIANG G, PERKINS SM, ZHANG C, KEER HN, LIU Y, NEPHEW KP, MATEI D: Genomic and epigenomic signatures in ovarian cancer associated with resensitization to platinum drugs. Cancer Res 78: 631-644, 2018. https://doi.org/10.1158/0008-5472.CAN-17-1492

GHANEM T, BRACKEN J, KASEM A, JIANG WG, MOKBEL K: mRNA expression of DOK1-6 in human breast cancer. World J Clin Oncol 5: 156-163, 2014. https://doi.org/10.5306/wjco.v5.i2.156

GUGASYAN R, QUILICI C, I ST, GRAIL D, VERHAGEN AM, ROBERTS A, KITAMURA T, DUNN AR, LOCK P: Dok-related protein negatively regulates $\mathrm{T}$ cell development via its RasGTPase-activating protein and Nck docking sites. J Cell Biol 158: 115-125, 2002. https://doi.org/10.1083/jcb.200112066

GUITTARD G, GÉRARD A, DUPUIS-CORONAS S, TRONCHÈRE H, MORTIER E, FAVRE C, OLIVE D, ZIMMERMANN P, PAYRASTRE B, NUNÈS JA: Cutting edge: Dok-1 and Dok-2 adaptor molecules are regulated by phosphatidylinositol 5-phosphate production in T cells. J Immunol 182: 3974-3978, 2009. https://doi.org/10.4049/jimmunol.0804172

GRIMM J, SACHS M, BRITSCH S, DI CESARE S, SCHWARZ-ROMOND T, ALITALO K, BIRCHMEIER W: Novel p62dok family members, dok-4 and dok-5, are substrates of the c-Ret receptor tyrosine kinase and mediate neuronal differentiation. J Cell Biology 154: 345-354, 2001. https://doi.org/10.1083/jcb.200102032

GÉRARD A, FAVRE C, GARÇON F, NÉMORIN JG, DUPLAY P, PASTOR S, COLLETTE Y, OLIVE D, NUNÈS JA: Functional interaction of RasGAP-binding proteins Dok-1 and Dok-2 with the Tec protein tyrosine kinase. Oncogene 23: 1594-1598, 2004. https://doi.org/10.1038/sj.onc.1207283

HERBET A, COSTA N, LEVENTOUX N, MABONDZO A, COURAUD JY, BORRULL A, HUGNOT JP, BOQUET D: Antibodies targeting human endothelin-1 receptors reveal different conformational states in cancer cells. Physiol Res 67 (Suppl 1): S257-S264, 2018. https://doi.org/10.33549/physiolres.933848 
HUGHAN SC, WATSON SP: Differential regulation of adapter proteins Dok2 and Dok1 in platelets, leading to an association of Dok2 with integrin alphaIIbbeta3. J Thromb Haemost 5: 387-394, 2007. https://doi.org/10.1111/j.1538-7836.2007.02307.x

HE PF, XU ZJ, ZHOU JD, LI XX, ZHANG W, WU DH, ZHANG ZH, LIAN XY, YAO XY, DENG ZQ, LIN J, QIAN J: Methylation-associated DOK1 and DOK2 down-regulation: Potential biomarkers for predicting adverse prognosis in acute myeloid leukemia. J Cell Physiol 233: 6604-6614, 2018. https://doi.org/10.1002/jcp.26271

HUANG J, PENG X, ZHANG K, LI C, SU B, ZHANG Y, YU W: Co-expression and significance of Dok2 and Ras p21 protein activator 1 in breast cancer. Oncol Lett 14: 5386-5392, 2017. https://doi.org/10.3892/ol.2017.6844

JAMBOR T, KOVACIKOVA E, GREIFOVA H, KOVACIK A, LIBOVA L, LUKAC N: Assessment of the effective impact of bisphenols on mitochondrial activity and steroidogenesis in a dose-dependency in mice TM3 Leydig cells. Physiol Res 68: 689-693, 2019. https://doi.org/10.33549/physiolres.934200

JONES N, CHEN SH, STURK C, MASTER Z, TRAN J, KERBEL RS, DUMONT DJ: A unique autophosphorylation site on Tie2/Tek mediates Dok-R phosphotyrosine binding domain binding and function. Mol Cell Biol 23: 2658-2668, 2003. https://doi.org/10.1128/MCB.23.8.2658-2668.2003

JONES N, DUMONT DJ: Recruitment of Dok-R to the EGF receptor through its PTB domain is required for attenuation of Erk MAP kinase activation. Curr Biol 9: 1057-1060, 1999. https://doi.org/10.1016/S09609822(99)80458-8

KAJIKAWA S, TAGUCHI Y, HAYATA T, EZURA Y, UETA R, ARIMURA S, INOUE JI, NODA M, YAMANASHI Y: Dok-3 and Dok-1/-2 adaptors play distinctive roles in cell fusion and proliferation during osteoclastogenesis and cooperatively protect mice from osteopenia. Biochem Biophys Res Commun 498: 967-974, 2018. https://doi.org/10.1016/i.bbrc.2018.03.090

KUŽMA M, KILLINGER Z, JACKULIAK P, VAŇUGA P, HANS D, BINKLEY N, PAYER J: Pathophysiology of growth hormone secretion disorders and their impact on bone microstructure as measured by trabecular bone score. Physiol Res 68 (Suppl 2): S121-S129, 2019. https://doi.org/10.33549/physiolres.934303

LAROCHE-LEFEBVRE C, YOUSEFI M, DAUDELIN JF, CHARPENTIER T, TARRAB E, KLINCK R, LAMARRE A, LABRECQUE N, STÄGER S, DUPLAY P: Dok-1 and Dok-2 regulate the formation of memory CD8+ T cells. J Immunol 197: 3618-3627, 2016. https://doi.org/10.4049/jimmunol.1600385

LYONS A, DOWNER EJ, COSTELLO DA, MURPHY N, LYNCH MA: Dok2 mediates the CD200Fc attenuation of Aß-induced changes in glia. J Neuroinflammation 9: 107, 2012. https://doi.org/10.1186/1742-2094-9-107

LAHMIDI S, STRUNK U, SMILEY JR, PEARSON A, DUPLAY P: Herpes simplex virus 1 infection of T cells causes VP11/12-dependent phosphorylation and degradation of the cellular protein Dok-2. Virology 511: 66-73, 2017. https://doi.org/10.1016/j.virol.2017.08.018

LAHMIDI S, YOUSEFI M, DRIDI S, DUPLAY P, PEARSON A: Dok-1 and Dok-2 are required to maintain herpes simplex virus 1-specific CD8(+) T cells in a murine model of ocular infection. J Virol 91: e02297-16, 2017. https://doi.org/10.1128/JVI.02297-16

LAMKIN TJ, CHIN V, YEN A: All-trans retinoic acid induces p62DOK1 and p56DOK2 expression which enhances induced differentiation and G0 arrest of HL-60 leukemia cells. Am J Hematol 81: 603-615, 2006. https://doi.org/10.1002/ajh.20667

LIANG X, HAJIVANDI M, VEACH D, WISNIEWSKI D, CLARKSON B, RESH MD, POPE RM: Quantification of change in phosphorylation of BCR-ABL kinase and its substrates in response to Imatinib treatment in human chronic myelogenous leukemia cells. Proteomics 6: 4554-4564, 2006. https://doi.org/10.1002/pmic.200600109

LUM E, VIGLIOTTI M, BANERJEE N, CUTTER N, WRZESZCZYNSKI KO, KHAN S, KAMALAKARAN S, LEVINE DA, DIMITROVA N, LUCITO R: Loss of DOK2 induces carboplatin resistance in ovarian cancer via suppression of apoptosis. Gynecol Oncol 130: 369-376, 2013. https://doi.org/10.1016/j.ygyno.2013.05.002

MASHIMA R, ARIMURA S, KAJIKAWA S, ODA H, NAKAE S, YAMANASHI Y: Dok adaptors play antiinflammatory roles in pulmonary homeostasis. Genes Cells 18: 56-65, 2013. https://doi.org/10.1111/gtc.12016

MASHIMA R, HISHIDA Y, TEZUKA T, YAMANASHI Y: The roles of Dok family adapters in immunoreceptor signaling. Immunol Rev 232: 273-285, 2009. https://doi.org/10.1111/j.1600-065X.2009.00844.X 
MASHIMA R, HONDA K, YANG Y, MORITA Y, INOUE A, ARIMURA S, NISHINA H, EMA H, NAKAUCHI H, SEED B, ODA H, YAMANASHI Y: Mice lacking Dok-1, Dok-2, and Dok-3 succumb to aggressive histiocytic sarcoma. Lab Invest 90: 1357-1364, 2010. https://doi.org/10.1038/labinvest.2010.121

MASTER Z, JONES N, TRAN J, JONES J, KERBEL RS, DUMONT DJ: Dok-R plays a pivotal role in angiopoietin-1dependent cell migration through recruitment and activation of Pak. EMBO J 20: 5919-5928, 2001. https://doi.org/10.1093/emboj/20.21.5919

MIHRSHAHI R, BARCLAY AN, BROWN MH: Essential roles for Dok2 and RasGAP in CD200 receptor-mediated regulation of human myeloid cells. J Immunol 183: 4879-4886, 2009. https://doi.org/10.4049/jimmunol.0901531

MIHRSHAHI R, BROWN MH: Downstream of tyrosine kinase 1 and 2 play opposing roles in CD200 receptor signaling. J Immunol 185: 7216-7222, 2010. https://doi.org/10.4049/jimmunol.1002858

MIYAGAKI H, YAMASAKI M, TAKAHASHI T, KUROKAWA Y, MIYATA H, NAKAJIMA K, TAKIGUCHI S, FUJIWARA Y, MORI M, DOKI Y: DOK2 as a marker of poor prognosis of patients with gastric adenocarcinoma after curative resection. Ann Surg Oncol 19: 1560-1567, 2012. https://doi.org/10.1245/s10434-011-2157-6

MIYATA-TAKATA T, CHUANG SS, TAKATA K, TOJI T, MAEDA Y, SATO Y, YOSHINO T: Expression of T-cell receptor signalling pathway components in extranodal NK/T-cell lymphoma. Histopathology 73: 1030-1038, 2018. https://doi.org/10.1111/his.13728

NÉMORIN JG, DUPLAY P: Evidence that Llck-mediated phosphorylation of p56dok and p62dok may play a role in CD2 signaling. J Biol Chem 275: 14590-14597, 2000. https://doi.org/10.1074/jbc.275.19.14590

NIKI M, DI CRISTOFANO A, ZHAO M, HONDA H, HIRAI H, AELST LV, CORDON-CARDO C, PANDOLFI PP: Role of Dok-1 and Dok-2 in leukemia suppression. J Exp Med 200: 1689-1695, 2004. https://doi.org/10.1084/jem.20041306

OHSUGI T, WAKAMIYA M, MORIKAWA S, FUJITA M: Expression of DOK1, 2, and 3 genes in HTLV-1-infected T cells. Acta Virol 60: 211-213, 2016. https://doi.org/10.4149/av_2016_02_211

OHSUGI T: Effects of expressing human T-cell leukemia virus type 1 (HTLV-I) oncoprotein Tax on DOK1, DOK2 and DOK3 gene expression in mice. J Vet Med Sci 79: 935-938, 2017. https://doi.org/10.1292/jvms.17-0034

RIJKERS ESK, DE RUITER T, BUITENHUIS M, VENINGA H, HOEK RM, MEYAARD L: Ligation of CD200R by CD200 is not required for normal murine myelopoiesis. Eur J Haematol 79: 410-416, 2007. https://doi.org/10.1111/j.1600-0609.2007.00920.x

SMITH MJ, HARDY WR, MURPHY JM, JONES N, PAWSON T: Screening for PTB domain binding partners and ligand specificity using proteome-derived NPXY peptide arrays. Mol Cell Biol 26: 8461-8474, 2006. https://doi.org/10.1128/MCB.01491-06

SOLAREK W, KOPER M, LEWICKI S, SZCZYLIK C, CZARNECKA AM: Insulin and insulin-like growth factors act as renal cell cancer intratumoral regulators. J Cell Commun Signal 13: 381-394, 2019. https://doi.org/10.1007/s12079-019-00512-y

SUZU S, TANAKA-DOUZONO M, NOMAGUCHI K, YAMADA M, HAYASAWA H, KIMURA F, MOTOYOSHI $\mathrm{K}$ : p56(dok-2) as a cytokine-inducible inhibitor of cell proliferation and signal transduction. EMBO J 19: 5114-5122, 2000. https://doi.org/10.1093/emboj/19.19.5114

TANAKA Y, KULKEAW K, INOUE T, TAN KS, NAKANISHI Y, SHIRASAWA S, SUGIYAMA D: Dok2 likely down-regulates Klf1 in mouse erythroleukemia cells. Anticancer Res 34: 4561-4567, 2014.

UETA R, TEZUKA T, IZAWA Y, MIYOSHI S, NAGATOISHI S, TSUMOTO K, YAMANASHI Y: The carboxylterminal region of Dok-7 plays a key, but not essential, role in activation of muscle-specific receptor kinase MuSK and neuromuscular synapse formation. J Biochem 161: 269-277, 2017. https://doi.org/10.1093/jb/mvw073

VAN SLYKE P, COLL ML, MASTER Z, KIM H, FILMUS J, DUMONT DJ: Dok-R mediates attenuation of epidermal growth factor-dependent mitogen-activated protein kinase and Akt activation through processive recruitment of c-Src and Csk. Mol Cell Biol 25: 3831-3841, 2005. https://doi.org/10.1128/MCB.25.9.3831-3841.2005

VÉLEZ P, OCARANZA-SÁNCHEZ R, LÓPEZ-OTERO D, GRIGORIAN-SHAMAGIAN L, ROSA I, GUITIÁN E, GARCÍA-ACUÑA JM, GONZÁLEZ-JUANATEY JR, GARCÍA A: Alteration of platelet GPVI signaling in ST-elevation myocardial infarction patients demonstrated by a combination of proteomic, biochemical, and functional approaches. Sci Rep 6: 39603, 2016. https://doi.org/10.1038/srep39603 
WATERMAN PM, MARSCHNER S, BRANDL E, CAMBIER JC: The inositol 5-phosphatase SHIP-1 and adaptors Dok-1 and 2 play central roles in CD4-mediated inhibitory signaling. Immunol Lett 143: 122-130, 2012. https://doi.org/10.1016/j.imlet.2012.02.009

WEN X, ZHOU M, GUO Y, ZHU Y, LI H, ZHANG L, YU L, WANG X, PENG X: Expression and significance of DOK2 in colorectal cancer. Oncol Lett 9: 241-244, 2015. https://doi.org/10.3892/ol.2014.2672

YASUDA T, SHIRAKATA M, IWAMA A, ISHII A, EBIHARA Y, OSAWA M, HONDA K, SHINOHARA H, SUDO K, TSUJI K, NAKAUCHI H, IWAKURA Y, HIRAI H, ODA H, YAMAMOTO T, YAMANASHI Y: Role of Dok-1 and Dok-2 in myeloid homeostasis and suppression of leukemia. J Exp Med 200: 1681-1687, 2004. https://doi.org/10.1084/jem.20041247

YASUDA T, BUNDO K, HINO A, HONDA K, INOUE A, SHIRAKATA M, OSAWA M, TAMURA T, NARIUCHI H, ODA H, YAMAMOTO T, YAMANASHI Y: Dok-1 and Dok-2 are negative regulators of T cell receptor signaling. Int Immunol 19: 487-495, 2007. https://doi.org/10.1093/intimm/dxm015

ZHANG S, CHERWINSKI H, SEDGWICK JD, PHILLIPS JH: Molecular mechanisms of CD200 inhibition of mast cell activation. J Immunol 173: 6786-6793, 2004. https://doi.org/10.4049/jimmunol.173.11.6786

ZHANG S, PHILLIPS JH: Identification of tyrosine residues crucial for CD200R-mediated inhibition of mast cell activation. J Leukoc Biol 79: 363-368, 2006. https://doi.org/10.1189/jlb.0705398

ZHANG XW, WANG L, DING H: Long noncoding RNA AK089579 inhibits epithelial-to-mesenchymal transition of peritoneal mesothelial cells by competitively binding to microRNA-296-3p via DOK2 in peritoneal fibrosis. FASEB J 33: 5112-5125, 2019. https://doi.org/10.1096/fj.201801111RR

ZHANG Y, LI Y, WANG Q, SU B, XU H, SUN Y, SUN P, LI R, PENG X, CAI J: Role of RASA1 in cancer: A review and update (Review). Oncol Rep 44: 2386-2396, 2020. https://doi.org/10.3892/or.2020.7807 